\title{
Pandangan Guru Prasekolah di Kota Surakarta tentang Peran Mereka dalam Konteks Pendidikan Inklusif
}

\author{
Rini Setyowati ${ }^{1}$, Anita Wardani ${ }^{2}$, Diana ${ }^{3}$ \\ STKIP Singkawang ${ }^{1,3}$, Universitas Negeri Yogyakarta ${ }^{2}$, Indonesia \\ rini1989setyowati@gmail.com ${ }^{1}$, aneeta_wayway@gmail.com ${ }^{2}$
}

\section{Keywords : \\ Pendidikan inklusi, guru \\ prasekolah}

\begin{abstract}
Kunci utama dalam keberhasilan praktek pendidikan inklusi adalah peran dan tanggung jawab guru prasekolah. Tindakan yang efektif dalam pengaturan inklusi harus disadari oleh guru. Tujuan dari penelitian ini adalah untuk mengevaluasi persepsi guru prasekolah tentang peran mereka dalam konteks pendidikan inklusi. Peserta adalah 20 guru prasekolah yang memiliki setidaknya satu siswa berkebutuhan khusus dikelas. Pengumpulan data dilakukan melalui wawancara semiterstruktur dengan para guru. Hasilnya adalah guru mengetahui peran dan tanggung mereka dalam pendidikan inklusif, namun mereka memiliki kekurangan yang signifikan dalam pengetahuan dan strategi memadai yang digunakan untuk memenuhi peran mereka. Penelitian ini diharapkan mampu berkontribusi dalam menggali pandangan guru prasekolah terhadap peran mereka dalam konteks pendidikan inklusif serta meningkatkan pengetahuan dan strategi guru dalam memenuhi peran tersebut. disimpulkan bahwa guru kurang memiliki pengetahuan, kesadaran dan keterampilan tentang sifat dan persyaratan pendidikan inklusi. Guru harus dibimbing mengenai peran yang harus mereka jalankan dalam lingkungan inklusif dan keterampilan yang dibutuhkan dalam pelaksanaanya.
\end{abstract}




\section{PENDAHULUAN}

Guru mempunyai kedudukan yang tinggi dalam masyarakat dan dunia modenisasi sehingga membawa profesion perguruan ke tahap yang lebih mencabar. Guru berdepan dengan pelbagai tuntutan seiring dengan kemajuan dan kehendak semasa. Mereka memainkan peranan dominan dalam merealisasikan inspirasi agama, bangsa dan negara yang terkandung dalam falsafah pendidikan negara selain bertanggungjawab terhadap pelajarnya. Masnan, A. H., Anthony, N. E., \& Zainudin, N. A. S. (2019).

Pendidikan inklusif pada dekade terakhir ini sudah mulai menunjukkan perkembangan yang berarti di Indonesia (Suparno, 2010). Pendidikan inklusi juga dipandang sebagai agenda penting diseluh dunia, supaya dalam prakteknya anak berkebutuhan khusus dapat terlayani dengan sangat baik (Marketa and Alison, 2013). Guru merupakan peran utama dalam terlaksananya praktek pendidikan inklusi (Marketa dan Alison, 2013).

Dalam perilaku sosial individu, status dan peran adalah konsep penting dalam psikologi sosial. Status mengacu pada seperangkat tugas dan hubungan dalam sistem sosial yang ditentukan oleh norma yang diterima oleh masyarakat (Mehmet dan Veysel, 2019). Peran mengacu pada seperangkat perilaku yang diharapkan oleh lingkungan atau masyarakat (Feldman, 1995). Manfaat dasar peran adalah untuk menyediakan pembagian kerja, untuk menentukan perilaku individu yang diharapkan, untuk menyamakan tugas individu sesuai dengan tujuan, dan untuk membentuk definisi dari individu (Mehmet dan Veysel, 2019). Untuk menyadari manfaat pendidikan inklusif, guru prasekolah harus menunjukkan perilaku sesuai dengan status mereka. Secara keseluruhan, guru tidak menyadari peran mereka terkait dengan pendidikan inklusif. Metode yang digunakan guru tidak komprehensif atau tidak cukup efektif dalam melaksanakan peran merekai.

Ada beberapa penelitian yang mengevaluasi pandangan guru dalam konteks pendidikan inklusif. Anastasia dan Len (1994) didalam penelitiannya menyatakan bahwa guru harus mengembangkan kemampuannya agar pendidikan inklusif dapat berjalan sesuai dengan tujuan. Guru juga harus mampu dalam melaksanakan perannya dalam mendeteksi anak-anak dengan kebutuhan khusus di kelas, sehingga mereka mampu memberikan pelayanan yang tepat untuk setiap anak dengan kebutuhan khusus (Cahyaning dkk, 2016).

Tujuan dari penelitian ini adalah untuk mengevaluasi persepsi guru prasekolah tentang peran mereka dalam konteks pendidikan inklusi

\section{METHOD}

Penelitian ini menggunakan model fenomenologis, yang berfokus pada persepsi, pengalaman dan pemikiran individu secara mendalam dan mengeksplorasi temuan dengan pandangan holistik dari komponen-komponen (Bogdan dan Biklen, 2007; Creswell, 2013). Fenomenologi deskriptif, penelitian ini mencoba untuk menentukan fenomena apa yang dialami atau sedang dialami orangorang (Bogdan dan Biklen, 2007; Ersoy, 2016; Patton, 2002). Kami menerapkan model ini pada penelitian kami untuk mengevaluasi persepsi guru prasekolah tentang peran mereka dalam kaitannya dengan pendidikan inklusif. Peserta dalam studi fenomenologi dapat memberikan data yang terperinci dan kaya, sesuai dengan aturan penelitian kualitatif (Denzin dan Lincoln, 2005). Dalam penelitian fenomenologi, kualitas partisipasi lebih penting daripada kuantitas partisipan karena tujuannya bukan untuk menggeneralisasi. Oleh karena itu peserta harus berpengalaman dalam topik penelitian (Patton, 2002). Peserta adalah 20 guru prasekolah yang memiliki setidaknya satu siswa berkebutuhan khusus dikelas. Pengumpulan data dilakukan melalui wawancara semi-terstruktur dengan para guru. 


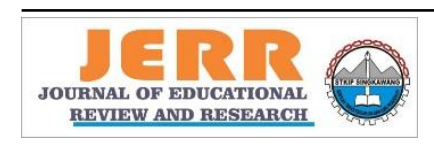

JOURNAL OF EDUCATIONAL REVIEW AND RESEARCH

Vol. 3 No. 2, December 2020. Page: 116 - 121

e-ISSN: 2597-9760, p-ISSN: 2597-975

\section{HASIL DAN PEMBAHASAN}

\section{Pandangan Umum tentang Inklusi}

Mayoritas guru menyatakan bahwa pendidikan inklusif sangat bermanfaat dalam meningkatkan perkembangan sosial anak. Sebanyak 12 guru menyatakan bahwa anak yang memiliki tingkat kecacatan yang parah tidak cocok dimasukkan kedalam kelas reguler. Hal ini diakibatkan karena tidak adanya guru pendamping khusus yang membimbing anak- anak $(n=11)$ dan kurangnya pelatihan tentang pendidikan inklusi yang didapat oleh guru kelas $(\mathrm{n}=10)$

\section{Penentuan IEP dan Keterampilan Prioritas}

Sebanyak 10 guru percaya bahwa merencanakan dan menegakkan program pendidikan inklusi akan berkontribusi pada pengembangan keterampilan siswa. 14 guru berpendapat bahwa untuk merencanakan dan menegakkan program pendidikan inklusi harus disiapkan tim. Sementara 6 guru berpendapat bahwa merekan bukan ahli untuk merencanakan dan menegakkan program pendidikan inklusi. Guru menyatakan bahwa keterampilan dalam bersosialisasi harus diajarkan kepada anak berkebutuhan khusus yang berada didialam kelas $(n=15)$. setelah keterampilan bersosialisasi, selanjutnya adalah kecerdasan potensial anak dengan kebutuhan khusus yang harus dikembangkan $(\mathrm{n}=15)$.

\section{Praktek Pembelajaran dan Evaluasi Anak-anak Penyandang Cacat}

Sebanyak 16 guru menyatakan bahwa mereka menggunakan berbagai strategi dan metode untuk menrencanakan dan menegakkan program pendidikan inklusi dan para guru juga menerapkan beberapa pratik pengajaran seperti, mengaja anak untuk ikut berpartisipasi dalam kegiatan $(n=7)$, menyesuaikan pembelajaran sesuai dengan kemampuan anak $(n=5)$, membantu anak dalam pembelajaran $(n=3)$, memberikan intekasi tatap muka $(n=2)$, dan memberikan dukungan $(n=1)$. Guru menyatakan bahwa evaluasi harus dilakukan secara berkala $(n=8)$. Namun ada 2 guru yang tidak melakukan evaluasi.

\section{Praktek Manajemen Perilaku untuk Anak-anak Penyandang Cacat}

Metode yang biasanya dilakukan guru untuk menangani perilaku bermasalah dari anak berkebutuhan khusus adalah memberikan peringatan secara verbal $(n=9)$, memberikan reward bagi anak yang menurut $(n=6)$, mengarahkan anak yang bermasalah kepada aktivitas lain $(n=3)$, dan membiarkannya saja sebanyak 2 guru. Namun terkadang cara mereka juga tidak selalu konsisten.

\section{Penerimaan Sebaya dan Keterlibatan Keluarga}

Semua guru $(n=20)$ berpendapat bahwa sangat penting untuk membuat anak-anak yang normal mampu menerima anak- anak penyandang cacat. Cara yang biasa guru gunakan adalah memberikan pengertian kepada anak-anak normal serta memberikan pengetian kepada orang tua anak-anak normal untuk ikut memberikan pengertian kepada anak mereka untuk merangkul teman sebaya mereka yang memiliki disabilitas.

\section{Peran Guru dalam Pendidikan Inklusif}

Mayoritas, sebanyak 11 guru berpendapat bahwa peran mereka adalah untuk mengajak siswa dengan kebutuhan khusus untuk mampu bersosialisasi. Peran yang lain adalah seperti memberikan bimbingan khusus kepada anak-anak disabilitas $(n=8)$ dan mengajak orang tua untuk ikut berpartisipasi dalam program pendidikan inklusi $(\mathrm{n}=7)$. 
Temuan penelitian bisanya sejalan dengan penelitian sebelumnya. Temuan pada penelitian ini menunjukkan bahwa pendidikan inklusi mampu mengembangkan kemampuan sosial anak serta perencanaan dan penegakan program pendidikan inklusi perlu untuk diadakan. Temuan dalam penelitian ini sejalan dengan penelitian- penelitian sebelumnya yang dilakukan di negara Indonesia. Seperti penelitian yang dilakukan oleh Nurul (2017) yang menyatakan bahwa pendidikan inklusi dapat menstimulasi perkembangan dan menanamkan karakter pada anak seperti saling membantu dan bermain bersama dengan teman yang memiliki disabilitas, anak dapat mengenal dan menghargai perbedaan yang ada, anak mampu memiliki rasa tanggung jawab, serta anak akan lebih terampil secara sosial. Mayoritas guru dalam penelitian ini menyatakan bahwa anak yang memiliki tingkat kecacatan yang parah tidak cocok dimasukkan kedalam kelas reguler ternyata sejalan dengan penelitian yang dilakukan oleh Syafrida (2013). syafrida berpendapat bahwa terdapat sekap negatif yang ditunjukkan guru terhadap anak penyandang disabilitas seperti memandang rendah kemampuan anak berkebutuhan khusus sehingga kurang cocok jika ditempatkan di kelas reguler.

Kurangnya pelatihan untuk guru, yang merupakan hasil didalam penelitian ini sejalan dengan pendapat dari Ririn (2014) dalam penelitiannya. Ririn menyatakan bahwa guru dengan latar belakang pendidikan inklusi lebih banyak memiliki pengetahuan tentang anak berkebutuhan khusus, sedangkan guru dengan latar belakang bukan dari pendidikan inklusi memiliki lebih sedikit pengetahuan tentang anak berkebutuhan khusus. Dapat disimpulkan bahwa pelatihan untuk guru dalam memahami pendidikan inklusi masih sangat kurang. Tidak adanya guru pendamping khusus yang membimbing anak- anak didalam kelas juga termasuk faktor yang mempengaruhi kesuksesan pendidikan inklusi di sekolah, sejalan dengan penelitian yang dilakukan oleh Awal (2017) yang menyatakan bahwa guru pendamping khusus sangat diperlukan untuk menjembatani anak-anak berkebutuhan khusus agar mampu mengikuti pembelajaran secara optimal.

Setengah dari responden menyatakan bahwa merencanakan dan menegakkan program pendidikan inklusi akan berkontribusi pada pengembangan keterampilan siswa disabilitas. Temuan ini sejalan dengan penelitian yang dilakukan oleh Awal (2017) yang menyatakan bahwa kurikulum yang tepat berbasis inklusi perlu dirancang karena kebutuhan masing- masing anak pun juga berbeda. Namun dalam penelitian Devi (2014) mengungkapkan bahwa kesiapan perencanaan program kegiatan pembelajaran untuk anak inklusi masih belum jelas, perencanaan kegiatan pembelajaran untuk anak inklusi yang dilakukan masih sama dengan perencanaan kegiatan pembelajaran yang dirancang untuk anak normal.

Mayoritas guru dalam penelitian ini menyatakan bahwa mereka menggunakan berbagai strategi dan metode untuk merencanakan dan menegakkan program pendidikan inklusi. Strategi dan metode yang direncanakan guru sejalan dengan penelitian yang dilakukan oleh Cahyaning, dkk (2016) yang menyatakan bahwa perencanaan yang matang dari guru terhadap anak berkebutuhan khusus dapat membantu untuk memberdayakan anak berkebutuhan khusus. Didalam penelitian ini guru menyatakan bahwa evaluasi harus dilakukan secara berkala. Hal ini juga sejalan dengan penelitian Cahyaning, dkk yang menyatakan bahwa masih terdapat $97 \%$ responden dalam penalitiannya yang belum melasanakan evaluasi terhadap anak berkebutuhan khusus, dan hal ini mengakibatkan guru belum mampu dalam menyusun strategi untuk menangani ana berkebutuhan khsusus.

Memberikan pengertian kepada orang tua anak-anak normal untuk ikut memberikan pengertian kepada anak mereka untuk merangkul teman sebaya mereka yang memiliki disabilitas adalah pendapat dari pada guru yang telah diwawancarai didalam penelitian ini dalam konteks pendidikan inklusi. Hasil ini konsisten dengan penelitain Cahyaning, dkk (2016) yang menyatakan bahwa melibatkan orang tua adalah hal yang penting dilakukan dalam konteks pembelajaran inklusi. Praktek manajemen perilaku guru untuk anak-anak berkebutuhan khusus konsisten dengan penelitian yang lainnya seperti memberi reward kepada siswa (Sukbunpant, 2013), dan memperingatkan mereka secara verbal (Sucuoğlu et al., 2010) 
Semua guru didalam penelitian ini berpendapat bahwa sangat penting untuk membuat anak-anak yang normal mampu menerima anak- anak penyandang cacat. Cara yang biasa guru gunakan adalah memberikan pengertian kepada anak-anak normal serta memberikan pengetian kepada orang tua anak-anak normal untuk ikut memberikan pengertian kepada anak mereka untuk merangkul teman sebaya mereka yang memiliki disabilitas ini sejalan dengan penelitian yang dilakukan oleh Fishel dan Ramirez (2005). Dalam kasus anak-anak dengan kebutuhan khusus, diharapkan bahwa keterlibatan orang tua sangat penting dalam mensukseskan pendidikan inklusi.

\section{KESIMPULAN DAN SARAN}

Dapat disimpulkan bahwa guru kurang memiliki pengetahuan, kesadaran dan keterampilan tentang sifat dan persyaratan pendidikan inklusi. Guru harus dibimbing mengenai peran yang harus mereka jalankan dalam lingkungan inklusif dan keterampilan yang dibutuhkan dalam pelaksanaanya.

Penelitian ini memiliki beberapa keterbatasan, yang pertama adalah penelitian ini dilakukan di daerah perkotaan. Hasil yang berbeda mungkin akan ditemukan ketika penelitian ini dilaksanakan didaerah pedesaan. Keterbatasan yang selanjutnya adalah hasil penelitian ini sulit untuk digenerelisasikan karena penelitian ini dilaksanakan dengan kelompok yang relatif sedikit.

Diharapkan penelitian selanjutnya dapat direncanakan dengan diadakannya pelatihan dan dukungan terhadap guru, karena dalam penelitian ini pandangan guru diteliti tanpa diberikan pelatihan ataupun dukungan apapun.

\section{DAFTAR PUSTAKA}

Anastasia, V., \& Len, B. (1994). Inclusive Education: Teachers and the Changing Culture of Schooling. British Journal of Special Education, Volume 21, No. 3, 105-107

Awal, K. (2017). Kurikulum Tingkat Satuan Pendidikan Berbasis Inklusi di Taman Kanak-Kanak. Jurnal As-Salam, 1(3), 90-97.

Bodie, Z., Kane, A., \& Marcus, A. J. (2002). Investments. Boston: McGraw Hill.

Brav, A., \& Heaton, J. B. (2002). Competing Theories of Financial Anomalies. Review of Financial Studies, 15, 575-606.

Cahyaning S., Tri, M. (2016) Pengembangan Model Deteksi Dini Anak Berkebutuhan Khusus Pada Tingkat Pendidikan Anak Usia Dini di Kota Malang. Jurnal Ilmiah Psikologi Terapan, Vol. 04, No.01.

Devi, M. (2014). Kesiapan Taman Kanak- Kanak Dalam Penyelenggaraan Kelas Inklusi Dilihat dari Program Kegiatan Pembelajaran. Journal of Early Childhood Education Papers, Vol 1, 18.

Garry, H. (2012) Inclusive Education For Children With Special Educational Needs: A Critique Of Policy and Practice In New Zealand. Journal of International and Comparative Education, Volume 1, Issue 1.

Garry, H. (2015). Inclusive Special Education: Development of A New Theory For The Education of Children With Special Educational Needs and Disabilities.British Journal Of Inclusive Special Education, Vol 42, No. 3, DOI: 10.1111/1467-8578.12101. 
Gezer, M., S., \& Aksoy, V. (2019). Perceptions of Turkish preschool teachers' about their roles within the context of inclusive education. International Journal of Early Childhood Special Education, 11(1), 31-42. DOI: 10.20489.

Indah, P., \& Binahayati R. (2012). Pelaksanaan Sekolah Inklusi di Indonesia. Prosiding KS: Riset \& PKM, Vol: 2, 147-300

Marketa, B., \& Alison, C. (2013) Continuing Professional Development (CPD) As A Means To Reducing Barriers To Inclusive Education: research study of the education of refugee children in the Czech Republic. European Journal of Special Needs Education. Vol. 28, No. 2, $203-$ 216,http://dx.doi.org/10.1080/08856257.2013.778108.

Masnan, A. H., Anthony, N. E., \& Zainudin, N. A. S. (2019). Pengetahuan pengajaran dalam kalangan guru prasekolah. Jurnal Pendidikan Awal Kanak-Kanak Kebangsaan, 8, 33-41.

McGinn, M. K., Roth, W. M., \& Bowen, G. M. (1998). How Prepared are Pre-Service Teachers to Teach Scientific Inquiry? Levels of Performance in Scientific Representation Practices. Journal of Science Teacher Education, 9(1), 25-48.

Nurul, K. (2017). Manfaat Program Pendidikan Inklusi Untuk Anak Usia Dini. Jurnal Pendidikan Anak, Volume 6, Edisi 1, 12-18.

Okey, A., Teng, L. (2008). Attaining Development Goals Of Children With Disabilities: Implications For Inclusive Education. International Journal Of Special Education. Vol 23, No $3,1-10$.

Suparno. (2010). Pendidikan Inklusif Untuk Anak Usia Dini. Jurnal Pendidikan Khusus. Vol.7, No.2.

Suzan, J. (2015). Education For All: A Historical Analysis of International Inclusive Education Policy and Individuals With Disabilities. Journal of Disability Policy Studies, Vol. 18 98-108.

Syafrida, E., \& Aryani T. (2013). Sikap Guru Terhadap Pendidikan Inklusi Ditinjau Dari Fator Pembentuk Sikap. Jurnal Psikologi Perkembangan dan Pendidikan, Vol. 2, No. 01, 1-10 